\title{
Using The Internet In Teaching Algebra To Middle School Students: A Study Of Teacher Perspectives And Attitudes
}

Maha Saad Alsaeed, King Faisal University, Saudi Arabia

\begin{abstract}
During the past decades, technological resources have been improved to support the teaching of mathematics. While the improvement of technological resources, the World Wide Web provides teachers and students many resources that engage students in rich mathematics experiences. There are a vast number of educational resources available through the Internet for students and teachers, which should be implemented in the classroom to support and improve algebra instructions. This study seeks to identify the extent of the middle school teacher's awareness of using the Internet to teach and develop students' learning of algebra. The participant's teachers in this study are teaching in schools located in a rural Appalachian region of a Midwestern state in the United States. The study found that the Internet's function in the algebra classroom within this particular group of middle childhood teachers are used for purposes that do not contribute to algebra instruction.
\end{abstract}

Keywords: Internet Resources; Algebra; Middle School Mathematics

\section{INTRODUCTION}

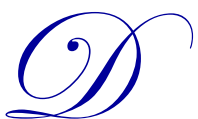

uring the past few decades, many organizations, projects and policies were established in the United States to support the use of technology in mathematics education, with the goal of improving quality of instruction. Educators are no longer dependent on physical manipulatives and other hand-held tools whose availability is restricted to some educational institutions, and many others that lack in mathematics resources.

Through the improvement of technological resources, the World Wide Web also provides teachers and students many resources that engage students in rich mathematics experiences. There are a vast number of educational resources through the Internet for students and teachers. The National Science Foundation, for example, funded online projects to engage students in meaningful mathematics learning environments, and there are a great many more with similar endeavors. The project is a National Library of Virtual Manipulative for learning mathematics for the grade levels k-8. Theses Online tools used for the purpose of teaching and learning of mathematical concepts. The tool is "an interactive, Web-based visual representation of a dynamic object that represents opportunity for constructing mathematical knowledge (Moyer, Bolyard \& Spikell, 2002)." It is online and Java-based, available for anyone who has access to the Internet on http://nlvm.usu.edu/en/nav/vlibrary.html. The National Council of Teachers of Mathematics (NCTM) has promoted another set of Java-based interactive tools through its Websites to support and reinforce mathematical concepts. In addition, on its Website the NCTM develops algebra lesson plans allowing teachers to incorporate these Java tools in engaging students in meaningful investments and reinforcement of algebra concepts. One example of such lesson plans created by the NCTM is pan balance-shapes virtual manipulative online tools which reinforce the equality concept. In this applet, students virtually interact with the algebraic concept of equality by placing shapes in the right and left side of the balance pan until they reach equality. After working with a virtual pan balance, the teacher can discuss with the students what they have done through the applet and allow the students in the classroom to reflect on their work. Within the discussion, students can link their findings to identify the equality properties and then use them to solve linear equations. In addition, more resources through the Web help teachers to improve mathematics teaching. Through these resources, teachers can use the Internet in the classroom to allow students to study mathematical concepts and enhance their reasoning and problem solving abilities. 
Teachers can allow students to access the Internet for many purposes, although not all of them are beneficial for the students. As is often the case in schools that have limited technology resources, the Internet can be used in the mathematics classroom for the purpose of decoration or glitziness (Herrera, 2001). This does not always translate into learning. For instance, in the above example of using pan-balance online tools, the teacher may start the lesson by viewing the pan balance applet on an overhead projector to show students how to work with them and might say "Okay, this is how to balance shapes. Now let see how to balance linear equations." Then he or she starts the lesson by providing the equality properties. In this example, students might have been motivated by the sound and color of the applets without the lesson contributing to learning the equality concept because the teacher did not provide students with a connection between what they saw on the screen and the mathematical concept. Thus, the Internet can be used to provide temporary, false motivation for students without actual results in student achievements.

Teachers can provide a multitude of opportunities for students to enhance their learning of algebra through the Internet. When teachers allow students to access the Internet for the purpose of contributing to the learning of algebra, it can assume three roles in the classroom:

1. As a tutor: Students can use the Internet individually to study or search for unfamiliar mathematical concepts. They can use Internet resources to answer questions provided by their teachers. They also can use the Internet to search for new concepts or make sure of incomprehensible new mathematics concepts. In this manner, the Internet can be used without the role of the teacher.

2. As a helper: As a helper for students working with concepts that cannot be treated without the technology. For example, students can use the Internet when dealing with extremely large numbers or extremely small numbers unmanageable with paper and pencil, or to perform graphing. In addition, students can use the Internet to receive updated data to explore and solve real-world problems that have mathematical applications. For example, students can work with updated data from the U.S Census Website (http://www.census.gov) for statistics or algebra classes.

3. As an environment: Teachers can create mathematics-rich environments for students to explore mathematical concepts by interacting with tools such as virtual manipulative online tools or graphing calculators. Teachers can allow students to work on these tools during instruction time to explore and further understanding of mathematical relationships or concepts.

The lack of understanding of how the Internet is used in classroom to improve algebra instruction among teachers led me to explore this area of research, and to investigate the problems that might prevent teachers from taking advantage of these learning resources. This study sought to answer the following question:

- Are mathematics middle school teachers who serve this rural student population aware of the importance of using the Internet learning resources in learning and teaching algebra?

- Are teachers providing mathematics-rich learning environments for students using the Internet learning resources?

- What are some problems that teachers who serve this rural student population face which prevent them from using the educational resources to teach algebra?

\section{PURPOSE AND SIGNIFICANT OF THE STUDY}

The purpose of the study was to gain a better understanding of how and to what extent currently practicing middle school math teachers use and benefit from the availability of the Internet in their schools to teach algebra topics. The study will provide insight to teacher educators and middle school mathematics teachers to consider these learning resources in enhancing teaching of algebra. The study allows supporters of the online mathematics educational resources to gain an understanding of the realistic uses of the online educational resources in the classroom. The study findings will help them identify some weaknesses in the function of the Internet in the classroom and suggest ways to improve educational Websites in order to ease the use of them by teachers and students. 


\section{REVIEW OF LITERATURE}

In the middle school, students are traditionally learning algebra concepts using different mathematical representations. They are learning how to represent quantitative relationships in symbols, graphs, and tables. They are no longer depending on only numbers, such as in the school of arithmetic in the elementary level symbolic. NCTM recommends that students should learn algebra topics including understanding patterns, relations and functions. They also should learn about representing and analyzing mathematical situations and structures using algebraic symbols such as solving word problems using algebra symbolism, especially problems that involved linear relationships. Furthermore, students in middle school should learn about using mathematical models to represent and understand quantitative relationships such solving word problems using graphs representation (NCTM, 2000)

Educational researchers advocate the importance of using the Internet's learning resources to inspire algebra classroom for middle school students and to reinforce the learning of its concepts. Many researchers show that students have difficulties in making transition from school of arithmetic in elementary schools to school of algebra in middle school or higher. This transition is difficult because students in middle and high schools are more likely to work with algebraic symbols in representing numerical relationships more than in the lower grades (NCTM, 2000). In addition, many of the students have difficulties in adjusting with manipulating abstract symbols that most of the time do not stand for anything for them (Kaput, 2000). Algebra, for some middle school students, has become a nightmare subject for many students while others refer to the subject with pride. Thus, finding new ways for students to motive and to engage students' interest and achieve in learning algebra is critically important to help students avoid the learning difficulties that many students in the middle grade experience in learning algebra. Suh, Moyer and Heo (2005) examine the achievement of fifth-grade students when using virtual manipulative in developing fraction concepts. The entire project was conducted at the elementary school computer lab, where all students have equal opportunity to access the virtual manipulatives through the Web. In detail, students were required to interact with two virtual manipulatives applets: The National Library of Virtual Manipulatives and one applet from the NCTM Webpage that used to reinforce fraction concepts. Students were interacting with applets to explore and do activities with the guide of the teachers. In this project, the researchers show that these technological tools empower many characteristics of learning the fraction concepts. In this project, virtual fraction manipulatives allow students to learn by discovering mathematical relationship through experimenting and testing conjectures. The tools supported and facilitated students' learning of fraction adding. In addition, the tools engaged students in the study to see and connect between mathematical representations of fractions and how to symbolize them.

Cavanugh, Gillan, Bosnick, Hess and Scott (2008), discuss in their project, which examines the effectiveness of using online learning tool in learning algebra, that teaching and learning with technology has a small positive effect on students' performance, including math learning. Also, they show through their experiment that the performance of students who are learning algebra with the interactive online tools was equivalent to that of not learning by the 'traditional' ways. So, this study presents some initial evidence that students who use the Internet resources were just as knowledgeable about algebra as the students who were taught in 'traditional' ways. Even though this result does not show the effectiveness of teaching and learning algebra using the Internet learning resources, however, this paper does suggest how such resources provide for students a mathematically rich learning environment.

\section{The Internet's Learning Resources Through the New Era of Teaching Algebra}

"The traditional images of algebra based in more than a century of school algebra, is one of the simplifying algebraic expressions, solving equations and learning the rules for manipulating symbols" (Kaput, 2000, p.2). Thus, for most of the time algebra has been taught and learned in the United States as a set of procedures and formulas that represent no meaning among other areas of mathematics or with the student's real world. Traditionally, as well as all other areas of mathematics, classroom teachers apply "behaviorist" learning approach in teaching algebra. In using behaviorist approach, students are acquiring new knowledge and behaviors and learn how to respond to these learning stimuli by negative or positive reinforcement (Pritchard, 2004). In this regard, through the traditional teaching of algebra, students are learning algebra by memorizing new formulas and procedures that they only know as operations on string symbols and old problems that are unrelated to their lives (Kaput, 2000). As students succeed in algebra, they are rewarded by higher test scores and other extrinsic motivation, while those students who are unsuccessful experience low testing scores and plenty of red "marks on their homework pages. The importance in 
the traditional algebra schools is to enable students to produce the right ways of manipulating symbols and procedures. In doing this, teachers do not allow students to reason or reflect on their answers, which in turn, disrespect students' thinking and creativity.

However, in the Era of Standards, the teaching of algebra in the United States has begun to gain a substantial change. NCTM (2000) advocates the importance of viewing algebra as a strand in the middle and elementary school curriculum by viewing Algebra standards. The expectation has been set to weave algebraic thinking throughout the whole spectrum of K-12 mathematics rather than having algebra be its stand-alone course that students take in eighth or ninth grade. In the NCTM, standards of algebra are no longer only moving symbols around; rather, it has been redefined as a need to understand the significant meaning of these concepts to apply them in their daily bases and to the other area of mathematics.

Students need to understand the concepts of algebra, the structure, and principles that govern the manipulation of the symbols and how the symbols themselves can be used to understand the life's situations (NCTM, 2000, p.37).

\section{Using the Internet as a Source of Teaching and Learning Can Support the New Era of Standards in Teaching Mathematics and Algebra}

In the new era of teaching mathematics and algebra, there is the emphasis on the constructivist approach of learning. Pritchard (2004) discusses in his book that using Internet learning resources will engage students in learning and reinforce the constructive approach of learning. Also, the Internet learning resources can change and influence the algebraic materials taught. Students can explore a large number of mathematical concepts without depending on traditional textbooks (Munshine, 2008; NCTM, 2000). They can explore problems with large numbers, problems associated with new mathematics such as fractal lessons and explore mathematical relationships through virtual manipulatives.

Furthermore, Internet resources can enrich the range and quality of investigation by providing a means of viewing mathematical ideas through multiple ways (NCTM, 2000; Suh, Moyer \& Heo, 2005). NCTM standards encourage teachers and students to explore mathematics from multiple representations and approaches in mathematical activities. For example, using online graphing tools, students are able to observe the graph of various functions, the model pattern of quantitative change and test some conjectures. Also, Patricia and Packenham (2005) discuss that online virtual manipulatives enable learners to view algebra from multiple representations, and it can serve as an open-ended content since students differ in using this applet to investigate and learn algebra. They show through their investigation in algebra classrooms that such manipulatives successfully encourage students to explore algebraic patterns because of the above features. Lastly, teaching mathematics using the World Wide Web can ensure the new approach of learning how to learn, where students are acquiring necessary skills to help them complete their journey in investigating new knowledge independently and constructing their understanding of algebraic concepts (Crane, 2000; Pritchard, 2004).

\section{The Internet's Learning Resources and Ensuring Learning Characteristics}

When teachers are integrating the Internet's learning resources into the content, many learning characteristics can be covered. The following paragraphs will review some relevant research studies that discusses some of these learning characteristics.

When middle school teachers create an environment where students use Internet resources to learn mathematics and algebra, they enable their students to investigate and to 'mathematize' the world around them. Teachers can create an ideal context for investigating the application of mathematics to the business world, the study of environment or animal habitats. Without the use of Internet sources, it will be more difficult for students to connect to the real world data that have mathematical applications (Herrera, 2001). One important collection of lessons that bring algebra to our real life was developed by Susan Boone (2004). One example that is appropriate for middle school students is called the Internet Pizza Server. Students are asked to create their pizza using choices of topping through the Website from actual online pizza restaurants. They will order the size of the pizza, determine the best to buy and cost per topping. They have to use their information about the area of circles and develop their problem-solving 
ability. Such examples can help middle school students bring algebraic formulas to the real life problems and connect the knowledge with other mathematical areas such as geometry and data collections. The Stowaway Adventure is a project designed by the Center for Innovation in Engineering and Science Education. This project can expose children to real-life mathematical problems where they use data from actual cargo ships at sea. Students use mathematics to calculate their ship's average speed in knots and to predict landfall (Herrera, 2001). Such example will help students to improve their way of reasoning and making decisions based on the data they use.

All these examples and thousands more advocate the NCTM vision for school mathematics, which believes that mathematics should be considered as a substantial science in a changing world. According to this vision:

The need to understand and be able to use mathematics in everyday life, and in the workplace, has never been greater and will continue to increase. Knowing mathematics can be personally satisfying and empowering. The underpinnings of everyday life are increasingly mathematical and technological. For instance, making purchasing decisions, choosing insurance or health plans, and voting knowledgeably all call for quantitative sophistication (NCTM, 2000, p.4).

Also, such real-life examples bring algebra to life, which is important for students' future careers. According to NCTM, "Algebraic competence is important in adult life, both on the job and as preparation for postsecondary education". The Internet enables students to explore and model phenomena and can assist them to understand the algebraic concepts behind these phenomena (Kaput, 2000). Through using the Internet's learning resources, students can connect mathematics to the world around them and in turn, participate in meaningful learning.

Using learning tools on the Internet to teach and learn mathematics can enhance the interactive engagement of students, their depth of learning, thinking and reasoning during the process of learning mathematics and algebra. Interactive engagement means that students are as close as possible to the content of what they are learning. It is the time when students are acquiring information by engaging in an experience that provides the basis for, or content of, their ensuing learning (Pritchard, 2004). Deep learning takes place when the learner becomes very involved in the tasks at the question. When students are interacting with a variety of media through the Internet, while also being allowed to feel as though they are a part of the subject matter, the important processes of learning algebra will be encouraged (Crane, 2000). The interactive online virtual manipulative empowers the interactivity in learning algebra because of its mathematical richness (Norris\& Johnson, 2006; Huetinck \& Munshine, 2008; Packenham, 2005). Suh and Heo (2005) make an attempt by their experiment to prove how online virtual manipulatives can reinforce important learning processes in teaching fractions to fifth-grade students and teaching mathematics in general. According to Cannon, Heal and Wellman (2000) a co- principal investigator for a National Science Foundation project which creates a Web-based National Library of Virtual manipulative for learning mathematics in K-8 grades, say the design philosophy of the online virtual manipulative that these applets are not only for watching clever animations. Indeed, a thoughtful interactivity and engagement is required in using these applets by students. An applet such as algebra tiles that are shown in the National Library of Virtual Manipulatives Website, needs learners to take action such as, to click select variable, drag or move an object to explore and visualize multiplying and factoring algebraic expressions (Cannon, Heal \& Wellman, 2000).

In using virtual manipulatives, teachers can help students to acquire their understanding of the concepts through Bruner's three stage of learning. In Bruner's theory students can successfully develop their understanding of concepts through the enactive, iconic and symbolic stage (Shulman, 2004). Through the enactive stages, students should interact with materials directly such as in this context engaging and interacting with virtual manipulative. Then, in the later two stages teachers can guide students in thinking through discussion until they reach a stage when they can symbolize the newly learned concepts. Thus, these online learning tools can help students to develop their understanding of concepts as exemplified through Bruner's first stage of learning and also help them to be aware of their learning and improvement processes.

When using the Internet educational resources in teaching algebra, it ensures one of the most important processes of learning mathematics in middle school which is communication. Communication is essential in the process of learning mathematics education, specifically in middle grades. NCTM advocates, "In classrooms where students are challenged to think and reason about mathematics, communication is an essential feature as students express the 
result of their thinking orally and in writing. This type of environment is desirable at all grade levels and in middle grades"(NCTM, 2000).

Crane (2000) indicates that in the Twenty-First Century, the main learning focus is on collaboration and team working activities. Careers nowadays require teamwork, problem solving and the ability to administrate diversity successfully. Technology and the use of the Internet in the classroom can empower communication for students in the classroom since working with the Internet requires working with others, receiving ideas, and sharing your own. Thus, the learning tools on the Internet are one of the most effective opportunities for students to communicate and share their developing insights and knowledge with other students (Pritchard, 2004; Lue\& Lue, 1999). The improvement of communication skills through the online learning tools is dependent on the teachers' role to encourage students to verbalize their mathematical thinking to themselves or peers. It is also dependent on their position as teachers in choosing the tasks that encourage the student's communication (Packenham, 2005; Suh, Moyer \& Heo, 2005). Finally, NCTM (2000) highly recommends the power of communication in middle-grade mathematics classroom:

During adolescence, students are often reluctant to do anything that causes them to stand out from their group, and many middle-grade students are self-conscious and hesitant to expose their thinking to others...Teachers should build a sense of community in middle grades classrooms, so students feel free to expose their ideas honestly and openly, without fear of ridicule (P. 268)

The online learning tools can facilitate students' connection between mathematical abstraction and concrete experiences between conceptual and procedural understanding. Other visual tools for algebra allow students to internalize a visual language and help students to work with complex algebraic concepts more easily. For example, graphic tools allow visual learners to visualize concepts in solving algebra problems (Cavanaugh, Gillan, Bosnick, Hess, \& Scott, 2008). Online virtual manipulatives could facilitate the connection between conceptual and procedural understanding because through these tools students visualize their understanding of concepts which facilitate applying the procedurals related to the concepts (Suh, Moyer, and Heo, 2005). For example, students can see how the visual model of fractions through the online virtual manipulatives which can help them to develop an understanding of fraction computations. Also, allowing students to transfer from concrete experiences to abstract thinking can be empowered through virtual manipulative and other algebraic computer software. As research indicates, algebraic symbolic can be meaningful for middle school students only if students are closely tied to concrete representations (Munshine, 2008).

\section{The Internet Learning Resources and Teachers' Position}

An important question should be asked, can Internet educational materials contribute to the learning of mathematics without the role of teachers, and how can (and should) the role of the teacher change from our traditional viewpoint when we consider the Internet as a teaching tool? Research shows that when students are accessing information through the Web, without the effective role of the teachers, the quality of learning carried out will be very poor with no results (Pritchard, 2004). Pritchard indicates that many bad habits will be encouraged with the absence or the lack of teacher roles such as addressing plagiarism or venturing into inappropriate Websites.

NCTM indicates that technology or the Internet should be considered as a teaching tool but should not take the place of teachers. Teachers should be the guide of students, observe their mathematical investigation, and reflect on their progress and results (NCTM, 2000; Huenink \& Munshin, 20008). When accessing information, teachers can encourage students to verbalize their mathematical investigation and share them with their classmates (Packenham, 2005; Suh, Moyer, \& Heo, 2005). This is why policymakers, educators, and leaders advocate the importance of providing technological training for teachers.

It was thought that computer literacy courses for teachers could support the effective teaching on how to use computers in their teaching. Recently, researchers' attention has turned to integrating technology into curriculum and providing training for teachers to use technological tools effectively. Being a competent computer teacher does not mean that you can teach students effectively using these tools (Wallace, 20004). However, the research that guide teachers to teach effectively in the area of technology and on the Internet are few comparing with the 
revolutionary development of technology through the Web (Huetinck \& Munshine, 2008; Assiri, 2003). In his doctoral thesis, Assiri (2003) shows important results regarding the use of the Internet through a sample of 83 high school teachers in Northwest Arkansas. The results show that teachers believe in providing training for teachers to achieve the effective teaching result of using computers in the classroom. Also, the results indicate that the secondary mathematics teachers in Northwest Arkansas are not aware of which area of mathematics they can use computers and the Internet in teaching the subject. The use of technology and the Internet is based on teachers' personal experiences and interest, and there are no policy guidelines for teachers to follow in regards to the use of technology and the Internet in Northwest Arkansas school districts.

Other studies show that many teachers who have an interest in using computers use them to record grades, review basic skills, write notes to parents or create worksheets. The same teachers are not integrating technology into the content they teach and in the daily lesson plan (Crane, 2000). As research shows that in the middle and high school, computers were being used primarily to create written documents or to teach computer skills. The same study indicates that only 6-7 percent of secondary mathematics classes were using computers as part of their discipline. All these studies above indicate that many teachers are not integrating the Internet into their teaching effectively to empower learning mathematics, or they are not aware of the importance of using the Internet in teaching mathematics and algebra, even though the majority of the teachers in the study are fairly competent with computers. It is important for teachers to recognize their important role in facilitating the use of Internet learning resources and their necessary education on how to use technology in their classrooms.

Teaching algebra in middle school is special. At the middle school, students are sensitive as they enter adolescence and experience emotional, physical and intellectual changes that mark and affect this stage of life and may relate to low academic achievements. Thus, students in the middle grades need teachers who are sensitive to their needs and engage them in a thoughtful learning environment. At this age, students also are growing more proficient with technology, particularly the uses of the Internet. Thus, using the Internet to reinforce algebraic concepts is natural and engaging to middle school students. As we found through the literature review that using the Internet learning resources as an aid to teach and learn algebra for students will approach the best learning environment. Of course, not all the learning resources that are provided on the World Wide Web are educationally equal and sites worth of our collective trust. There are many excellent resources for algebra on the Internet, but there are also many 'not-soexcellent' sites that have been created, too. We hope of the active role of the teachers that can make the access to the Internet learning resources is safe for our students and aim what we wish.

\section{METHODOLOGY}

\section{Research and Design}

The purpose of the study was to find out to what extent mathematics middle school teachers in a rural Appalachian region of a populous Midwestern state are aware of the importance in using the Internet in teaching and learning of algebra. A qualitative approach was used to gather and analyze the data. In order to gather the most accurate information about the Middle school teachers' use of the Internet in their classrooms, this study used in-depth interview questionnaire. I have developed the questionnaire which seeks information regarding the middle school teachers' current uses of the Internet in their classroom teachings. The findings of this study have the potential of helping mathematics educators and educational Web designers understand how students benefit from Internet educational resources in learning mathematics.

\section{Participants, Schools and the Communities}

\section{The Sitting}

The study took place in a rural Appalachian region of a Midwestern state in the United States. The participants came from three different school districts, two rural and one urban: City Middle School, Lincoln Middle School, and Maysville Middle School. 
The three schools exhibit differences of socioeconomics, and two of the schools are considered rural, one urban. All three schools have different statuses of mathematics achievement according to the state report card. According to the state educational Webpage, every school is required to have at least $75 \%$ of the students at or above the proficient level in mathematics to earn the state indicators, which are based on the state achievement test on math, writing, and reading. The school's various rankings according to these state requirements provide variables within the study.

\section{Marysville Middle School}

This school is located in a rural county in Midwestern U.S. The population of the county is 17,701 . The Median household income for the county is $\$ 32,636$ comparing with the state median income $\$ 41,460$, according to the recent U.S. Census. According to the state educational report card, the average daily enrollment in the school is 890 with $97.9 \%$ White (non-Hispanic) students. Almost half $(49.6 \%$ percent) of the students are considered economically disadvantaged, and $18.7 \%$ have disabilities. Also, $33 \%$ of the students are eligible for free lunch, and $12 \%$ of the students are eligible for reduced lunch.

In Marysville_Middle School, there are 55 teachers, and for every teacher, there are an average 17 students. All of the teachers are bachelor degree holders, and $69.1 \%$ of the teachers have at least a master's degree. In 2007, the school met the state indicators since $89.3 \%$ of the $6^{\text {th }}$ grades students, $78.9 \%$ of the $7^{\text {th }}$ grades students, and $83.2 \%$ of the $8^{\text {th }}$-grade students at Marysville. The school scored at or above the proficient level in mathematics. In addition, the Marysville middle school is in the improvement statue and has met the adequate yearly progress (AYP).

\section{Lincoln Middle School}

This school is located in a small rural county with a population of 6,520 . The median income of the residents is about $\$ 26,492$, compared with the household income of the state at $\$ 41,460$, according to the recent U.S. Census. According to the state report card, the average daily student enrollment in the school is 455 students, and $96.6 \%$ of them are Whites (non-Hispanic). The school population includes $68.8 \%$ students considered economically disadvantaged and $14.5 \%$ with disabilities. Also, $49 \%$ of the students are eligible for free lunch, and $10 \%$ of them are eligible for reduced lunch.

Lincoln Middle School has 33 teachers, and for every teacher, there are 15 students. All of the teachers in the school have a Bachelor's degree, and almost half of them have at least a Master's degree in their content area. According to the Ohio Department of Education Webpage, in 2007-2008 the school did not meet the state's proficiency indicator in mathematics achievement. Only 65.2 of $6^{\text {th }}$ graders, $69.9 \%$ of the seventh graders and 74.6 $\%$ of the eighth graders scored at or above the proficient level of $75 \%$. The school report card places the school in "Effective" status with unmet Adequate Yearly Progress AYP.

\section{The City School}

Unlike the two schools above, this school is located within a small urban area. The population is 31,225 with the average age of 22 , largely because of the nearby university with approximately 20,000 students on campus. This city has median household income $\$ 25,889$. According to the state educational report card, the City School average daily enrollment is 475 students, and $90.7 \%$ are white. The City School has $19.9 \%$ students with a disability, and $33 \%$ are considered economically disadvantaged. Twenty-six percent of the students are eligible for free lunch, and $5 \%$ are eligible for reduced lunch.

In the City School, there are 37 teachers with average 13 students for every teacher. The state educational report card indicates that $77 \%$ of the teachers in the school are at least Master's Degree holders. The state report card for the year 2007-2008 year reports that the school did not meet the state indicator in mathematics because of only $67.6 \%$ of $7^{\text {th }}$ graders, and $67.8 \%$ graders scored at or above the proficient level in the state mathematics achievement test. Furthermore, it reports that the school is "at-risk" status and did not meet the Adequate Yearly Progress AYP.

Each of the three schools has computer labs available for teachers to use and free Wi-Fi accesses available to students and teachers. The computer labs provide students with free yet supervised access to the Internet. 


\section{Participants}

The study gathers qualitative data from 9 mathematics teachers selected from the three different middle school districts located in the Appalachian region of the Midwestern United States: City Middle School, Lincoln Middle School, and Maysville Middle School. All the three schools contain between four to five middle school mathematics teachers. The name of the three schools and their county are kept anonymous; pseudonyms are used to protect participants' privacy. The selection of the participants depends on their willingness to participate in the study and who considered being " information -rich cases"(Patton, 2002, p.230). Also, the nine participants are teaching algebra in six, eight and ninth grades. Sixth-grade teachers are teaching algebra per the state standards. Seventh-, eighth-, and ninth-grade teachers are teaching pre- algebra and algebra I.

\section{DATA COLLECTIONS}

The data were collected through an interview questionnaire. The questionnaire consists of fifteen pre-structured open-ended questions. The first three questions in the questionnaire sought to ensure that the participants teach algebra at the middle school level because it is the target in this study. Then I provided questions to identify the theme of the curriculum that the participants are currently using in teaching algebra, as well as any other resources besides textbooks they use in class. These questions bring insights of the teachers' approaches and attitudes in teaching algebra which shows why teachers answer in certain ways and helps to provide recommendations. Other questions aim to investigate the teachers' current use of the Internet in teaching algebra. Also, I included a question that asked teachers to identify the advantages and disadvantages of using the Internet in teaching algebra to middle school students.

\section{DATA ANALYSIS}

All the voluntary participants in this study completed the interview questionnaire. The questionnaire contained fifteen open-ended questions carefully analyzed using open coding. All codes were grouped, and a connection among them was identified. Then, I develop selective coding, which refers to the processes of selecting the core category that are dominant across most participants and which explain my research question (Strauss\& Corbin, 1990). Selective codes helped in developing the overreaching themes that explain and answer the research questions. Six themes are discussed in the following paragraphs

\section{FINDINGS}

Participants in this study discussed the level of their usage of internet resources in teaching algebra. Analyzing of the data indicated six themes that will be presented separately.

\section{Curriculum Type}

The teachers in this study are using various curriculums of a different focus in teaching algebra. Seven of them are using teacher-centered curriculum while only two of the middle school participants teachers are using studentcentered or reform-based curriculum in teaching algebra. The finding of this section is summarized in Table 1.

Table 1. The number of the teachers that are using a certain type of curriculum.

\begin{tabular}{l|c}
\hline \multicolumn{1}{c}{ Type of curriculum } & Number of participants \\
\hline Student-center curriculum & 7 \\
\hline Teacher-center curriculum & 2 \\
\hline Total & Nine teachers \\
\hline
\end{tabular}




\section{Material Besides the Textbooks Utilized by the Participants}

Two teachers indicate that he or she utilizes materials other than the textbooks to teach algebra. One uses worksheets; the other teacher names an informational book that helps educators integrate algebra and mathematics in teaching.

Also, teachers discuss their level of allowing students to use physical materials when learning algebra. Three of the teachers said they use and allow students to use calculators daily in the classroom. Three of the participant teachers indicate that they are using hand-held manipulatives with the students in teaching algebra while five of them say that they never use physical or hand-held manipulatives with the students in teaching algebra. Furthermore, one teacher said that he or she is planning to use a hand-held manipulative for the first time to teach students algebra. Table 2 provides a summary of the findings in this section.

Table 2. The number of the participants and their level of allowing students to use of physical manipulatives.

\section{$\begin{array}{ll}\text { The participants' level of allowing students to use physical manipulative } & \text { The number of the participants }\end{array}$}

Never allow students to use them

Allow students to use them every day in algebra class

Willing to allow students use them next year

Total

5

3

1

9

\section{The Participants' Use of the Internet in Teaching Algebra}

I asked the teachers to describe their general use of the Internet in teaching algebra. Four teachers out of nine said that they are using the Internet to prepare their students for the state achievement test. All of these four participants mention that they use a Website (I call it math study) that provides a drill-and-practice approach to the questions on the standardized test. This Website is designed to help students practice to pass the state achievement test. Also, one of the teachers said that using the Internet to prepare students for the achievement test is not optional because the school administrator requires periodic Internet practice session for testing. Furthermore, three of the participants said they use the Internet to help students practice the newly taught concepts and for research to clarify the new concepts. Only one of the participants said that he or she uses the Internet in teaching algebra, by searching for updated relevant word problems to let students work on them. One of the overall participants said that he or she never use the Internet in teaching mathematics. Table 3 shows the number of the educators and their different purposes in using the Internet to teach algebra.

Table 3. The number of the teachers and their purposes in using the Internet to teach algebra.

\begin{tabular}{l|c}
\hline \multicolumn{1}{|c}{ The purpose of using the Internet in teaching algebra } & The number of the participants \\
\hline Preparing for the achievement tests & 4 \\
\hline Integrating the Internet educational resources in teaching algebra & 1 \\
\hline For general practice & 3 \\
\hline Does not use it & 1 \\
\hline Total & 9 \\
\hline
\end{tabular}

I asked in my questionnaire the teachers to provide the Websites that they use for their students to teach algebra. Eight of the teachers said that they are using the Math Study Website to prepare students for achievement testing. Two of the teachers said that they are utilizing Websites such as the NCTM site and educational help Website to find lesson plans for teaching algebra.

To summarize the findings in this section, eight of the participants indicate that they do not allow students to use the Internet in learning algebra as part of the instruction time except, at most, once every two weeks to prepare for the standardizes tests. However, only one of the teachers said that they are giving students homework assignment on the Internet, but such assignments must be optional for the students because not all of them have Internet access away from school. 


\section{The Teachers and the Use of Online Virtual Manipulative}

All of the participant teachers say they never allow their students to use virtual manipulatives in learning algebra. However, one of these teachers plans to allow students to use virtual manipulatives starting next year. The teacher said that he wants the students to practice moving graphs of a linear equation and notice the trends or what happens to the slope when the graphs are changed.

\section{Advantages and Disadvantages of Using the Internet in Teaching Algebra}

The teachers note what they saw as advantages in using the Internet in teaching algebra. One teacher said that the use of the Internet in the classroom allows students to work at their paces and helps provide differentiated instruction for students with the distinct ability in mathematics. In the finding of this study, this only applies to the Math Study program, and not the consistent use of the Internet to build conceptual understanding of algebra. Another teacher mentions that the Internet is important for visual learners who understand mathematics better when they interact with real objects such as Internet Websites. Also, one teacher said that students enjoy learning and find motivation through the Internet work.

The only disadvantage that all the participants agree with is that using the Internet in teaching mathematics and algebra is not always applicable due to the limitation of computers access in their schools. Teachers report that there are only one to two labs in their schools. These computer labs are not available as often as they need them because they are shared by other classes in the school. Another application limitation is that one teacher perceives the Internet as detracting too much time from a wide list of topics necessitating coverage in limited instructional periods.

\section{DISCUSSION OF FINDINGS}

This study explores the level of middle school usage of Internet learning resources in teaching algebra. The interview of the participants indicates common themes regarding their current usage of internet resources. In this section, I attempt to answer the research question based on the emerging themes of the data.

Are middle school mathematics teachers who serve this rural student population aware of the importance of using the Internet learning resources in learning and teaching algebra?

From their responses, the participant teachers mention that there are many advantages of using the Internet in teaching algebra. The teachers declare that: Internet Mathematics resources is "allowing students to work according to their individual abilities and providing instruction respectful of all the students' abilities"(Participant 1). Also, other participant said that the" use of the Internet in teaching algebra might help visual learners learn better." Thus, the teachers are aware of the benefits of using educational Websites in teaching algebra. However, this small-scale study shows evidence that the teachers do not understand when and how the use of the Internet is important for the students in teaching algebra.

The first evidence of this is the teachers' restricting student use the Internet during the time of instruction. Also, if the teachers allow their students to use the Internet, they do so only in the evaluation part of the instruction. Teachers thought of the educational Websites as useful only for assessment and tests general practices, not for teaching and reinforcement of algebra concepts. This is evident from the study's indication that seven of the participants are using the Internet in preparing for large-scale assessments or general practice (see Table 3). Also, the middle school math teachers from the three different school districts are using the Math Study Website, which illustrates that their general use of the Internet aims to prepare to assess student understanding of previous lessons and to prepare students for the high-stakes test that they will take in the Spring of each academic year. Thus, many teachers know the importance of using the Internet in teaching algebra, but they do not know in which part of instruction it can be used.

The second evidence which shows the teachers' misunderstandings of the benefit of using the Internet is that students are using the Internet without any guidance of the teachers. Only one of the nine participants assigned homework on the Internet. The rest of the teachers said that they do not allow their students to use the Internet in the 
time of the instruction. These findings indicate that students are using the Internet without any guidance from the teachers, which does not improve the students learning of algebra as illustrated in the literature review.

Are teachers providing for student's mathematics-rich learning environment using the Internet learning resources?

Only one teacher from the participants indicates that he or she is using the Internet for a purpose other than preparing for tests. This teacher's purpose of using the Internet is to enrich the students' learning environment by providing new and relevant word problem for algebra class. The other educators are not using the Internet educational resources as part of an enriching and enhancing the learning of algebra.

Through the literature review, it is discussed how the online virtual manipulatives can provide an ideal learning environment for the students and enhance many of the learning characteristics such as developing students' communication and problem-solving abilities, and can also support meaningful learning as explicated by Bruner in the stages of constructing meaningful learning. The findings of the study indicate that none of the participants integrate these online tools for teaching algebra.

What are some problems that teachers in these schools face which prevent them from using the educational resources to teach algebra?

In the study, it is clearly shown and the heavy emphasis of the teachers on their students to have high grades on the achievement tests. High grades do not always translate into signs of well-connected and well-constructed content knowledge in the minds of the students. Also, the school administrations are asking teachers only to help students pass these standardized tests. However, students' ways of learning, their enjoyment and their deep understanding of algebra concepts are not emphasized by the teachers and the school administrations. Indeed, as it is discussed in the literature that using Internet educational resources effectively in teaching algebra is one way that can improve the students' achievement.

Another important problem that should be discussed and is put forth by the participants is the limitation of access to the Internet in the schools. Although all three schools in this study have computer labs with enough computers for every classroom students, the teachers in the same schools indicate that they lack optimal access to these computer labs. Therefore, this creates a major barrier for educators' further use of the Internet in teaching algebra.

\section{Implications for Educators and Researchers}

The implication based on the study's findings is presented in this section. The present study recommendation for the further researcher, teachers, and educators.

Further research on student achievements based on using the Internet to learn algebra will strengthen and validate the findings of this study. Another important study would repeat this study with a large group of teachers, such as school districts in a particular state. Also, one of the findings in this study shows that teachers have an interest in using the online virtual manipulative in teaching geometry. Thus, additional research on using the online virtual manipulatives to teach other areas of mathematics besides algebra would provide valuable information about the use of the Internet in teaching other branches of mathematics.

Teachers, while they may desire to be proficient with teaching mathematics by technology, are facing barriers and not engaging fully with the possibilities. Therefore, in the following paragraphs, I discuss the teacher's methods for mathematics education, their implications, and suggestions that could bring about higher learning and mathematics proficiencies among students. Theses recommendation were emerged through the course of analyzing the findings of the data

The teachers should emphasize the students and their processes of learning, not specific outcomes.

Currently, there is great emphasis on shifting the goal of mathematics instruction toward the development of the student process of learning, creativity and thinking (Shulman, 2004). However, the findings of this study indicate 
that many middle school mathematics teachers are still not aware of such changes. It has been shown that teachers and schools administrators are heavily emphasizing what the students are learning and what they score on the achievement tests, instead of considering the improvement of their learning process. Also, as it is discussed in the literature review, one way that teachers can use the Internet in the classroom ensures the development of students' process of learning, thinking, and creativity is to consider the use of the online educational resources in teaching algebra (Pritchard, 2004). Thus, teachers and the school administrators must be encouraged into the movement of shifting the goal of school of mathematics toward the students' learning process. They should actively consider and seek the ways, teach methods, materials, and textbooks that allow them to focus on the development of the student process of learning. And it's important that they consider advancing technology as they seek ongoing professional development.

Furthermore, teachers and educators should be aware of the student-centered approach to learning mathematics, in which the students and their thinking and creativity are the objects of instruction. One important aspect of the student-centered approach is posing to the student's relevant word problems (Brooks \& Brooks, 1999). In the literature review, it is shown that teachers can find and pose relevant problems that meet the students' interests by using Websites that provide relevant problems. Another aspect of the student-centered approach is that students need to be actively engaged and interact with real objects (such as using physical or online manipulative) as part of developing their understanding. This is discussed in the literature review as the first stage of Bruner's stages of development. In Bruner's stages of developing student understanding, students need to be actively engaged with real objects. However, the findings of this study indicate that teachers are neither using the online nor physical manipulatives in teaching to allow students interact with real objects since most middle school teachers have the belief that manipulatives are for kids. Consequently, educators are not considering the student-centered approach or any of its aspects. Other findings show that teachers are not considering student-centered textbooks. Thus, one significant suggestion arising from this study deals with raising educators' awareness of student-centered approaches to teach, and how they are implemented in algebra teaching.

The students should be guided by the teachers when using the Internet learning resources.

In the literature review, it is presented that without the effective guidance of the teachers, the use of the online educational resources in teaching algebra will not play its effective role. However, the findings of this study show that while there is a limitation of the students' access to the Internet in the classroom, students use the Internet in their schools without the guidance of educators. The participant teachers in this study asked their students to use the Internet learning resources either at their homes or in school to practice for achievements tests individually. Consequently, it is recommended from this study for students to use the Internet learning resources with the guidance of the teachers as part of the instruction. Teachers should be responsible to choose the Websites that students can use in learning algebraic concepts. Another important job for teachers is to choose tasks that allow students to express their thinking and creativity and that are tied to the concepts taught in class. For example, NCTM provides through its Website lesson plans that guide teachers to use the online virtual manipulative in teaching algebra successfully.

\section{CONCLUSION}

This study sought responses on the following topics: understanding the extent that mathematics middle school teachers are aware of the importance of using the Internet learning resources in learning and teaching algebra; seeing the extent that teachers provide mathematics-rich learning environments for students using Internet learning resources; and identifying the problems that teachers face which prevent them from using online educational resources to teach algebra.

The finding of this small-scale study indicates that teachers are misunderstanding or may not clearly see the educational advantages of using online resources to build an understanding of algebra or the valid role of the Internet for learning mathematics. The study found that teachers are mainly using the Internet to help students practice for general practice and prepare for standardized testing. Thus, the use of the Internet is restricted in the evaluation part of the instruction. Teachers are not integrating the Internet in the instruction time to provide mathematically-rich learning environments for students. Also, students are not using the Internet with the guidance 
of the teachers, as they are using it only for individual practices. Also, teachers indicate that the school administrators are allowing the use of the Internet only in preparation for achievement tests, showing that there is a limitation of the teachers' time to access computer labs that are available in the schools. Teachers report that the busy schedule of the schools' computers labs is not supporting a quest for integrating the Internet into teaching and learning algebra.

Overall, the study found that students benefit from using the Internet in learning algebra, according to the teachers in the literature review. Students in middle schools are enjoying working with technology in the classroom. Also, the literature review shows that many learning characteristics can be developed when using the Internet in teaching algebra.

While the validity of this study faces certain limitations mostly due to sample size, it has definite possibilities for future research topics. I learned that educators' attitudes toward the use of the Internet in the classroom, especially in this limited population, is one of the most critical issues in determining whether students benefit from the Internet in learning algebra. While teachers in this study seem to recognize the various benefits of using the Internet in teaching algebra, their use of the Internet is restricted for reasons including logistics of sharing computer labs in schools, demanding teaching loads in an environment of high-pressure standardized testing, and administrator's support. This last issue emerged during the study, indicating the possibility of administrators' attitudes toward the Internet as frivolous, rather than as an opportunity for efficient learning. The administrators' attitudes could also be tied to the school's need to attain the "effective school" designation from the test scores as well. For example, if a school needs to improve to meet "effective" designation, administrators might see Internet learning as a diversion from that goal. The administrators' attitudes toward the use of the Internet may correlate dramatically with the access teachers have to computer labs and the Internet, but further data collection focusing on building principals' beliefs would need to be collected to warrant such a claim.

An essential question that arises during this study (or analyzing the results) is: What role does the Internet play in the classroom in teaching algebra: tutor, helper, or learning environment? All of the findings of this study show that students mainly use the Internet individually for practice and repetitive drill for previously learned mathematical concepts. That indicates that the role of the Internet in the classroom is as a tutor for the students. The Internet's actual role in the classroom only reinforces what the students previously learned, neglecting the possibilities of the Internet to contribute to overall algebra instruction. Teachers and administrators should call for considering the role of the Internet in their schools to be not only a tutor. Rather, they should consider it as a helper for the teachers to provide a learning environment that enhances and ensures student understanding and learning of algebra.

\section{AUTHOR BIOGRAPHY}

Maha Alsaeed has a Bachelors, Masters and PhD Degree in the field of Mathematics Education. She has taught Mathematics and Education classes at King Faisal University, Saudi Arabia. She served as Academic Coordinator of the female college of Computer Science and Information Technology at the University. Maha has lived and studied her graduate programs in USA. She has a deep interest in designing and implementing professional development programmes for Maths Teachers.

\section{REFERENCES}

Assiri, M. A. (2003). Exploring the attitude and practices of northwest arknsas high school mathematics teachers regarding technology. (AAT 3097296).

Brooks, J. G., and Brooks, M. G., (1999). In search for understanding: The case for constructivist classroom. Alexandria: Association for Supervision and Curriculum Development.

Cannon, L., Heal, R. \& Wellman, R. (2000). Serendipity in Interactive Mathematics: Virtual (Electronic) Manipulatives for Learning Elementary Mathematics. In C. Crawford et al. (Eds.), Proceedings of Society for Information Technology and Teacher Education International Conference 2000 (pp. 1083-1088). Chesapeake, VA: AACE.

Cavanaugh, C., Gillan, K. J., Bosnick, J., Hess, M., \& Scott, H. (2008). Effectiveness of interactive online algebra learning tools. Educational Computing Research, 38, 67-95.

Crane, B. E. (2000). Teaching with the Internet: Strategies and models for k-12 curricula. New York: Neal-Scuman.

Herrera, T. A. (2001).A valid role for the Internet in the mathematics classroom. Australian Mathematics Teacher, .57, 24. 
Huetinck, L., \& Munshin, S. N. (2008). Teaching mathematics for the $21^{\text {th }}$ century: Methods and activities for grades 6-12. Columbus, $\mathrm{OH}$ : Pearson Education.

Johanson, A., \& Norris, K. (2006). Teaching today's mathematics in the middle grades. The United State of America: Pearson Education.

Kaput, J. M. (2000). Teaching and learning a new algebra with understanding. Retrieved Wednesday, September 17, 2008, from Google Scholar.

Leu, D. J., \& Leu, D. D. (1999). Teaching with the Internet: Lessons from the classroom. Norwood: Christopher-Gordon.

National Council of Teachers of Mathematics. (2008). Algebra and algebraic thinking in school mathematics: Seventieth year book. Reston, VA: Author.

National Council of Teachers of Mathematics. (2000). Principles and standards for school mathematics. Reston, VA: Author.

Peckenham, P. S. (2005). Using virtual manipulatives to investigate patterns and generate rules in algebra. Teaching Children Mathematics, $11, \mathrm{p} .437$.

Pritchard, A. (2004). Learning on the net: A practical guide to enhancing learning in primary classroom. London: David Fulton.

Shulman, L.S. (2004). Psychology in mathematics education. In S.M Wilson (Ed). The wisdom of practice (pp.49-96). San Francisco, CA: Jossey- Bass.

Suh, J., Moyer, P. S., \& Heo, H. (2005). Examine technology uses in the classroom: Developing Fraction sense using virtual manipulative concept tutorials. Journal of Interactive Online Learning, 3, 1-21. 
NOTES 